\title{
Natural Philosophy and the Use of Causal Terminology: A Puzzle in Reid's Account of Natural Philosophy
}

\begin{abstract}
:
Thomas Reid thinks of natural philosophy as a purely nomothetic enterprise but he maintains that it is proper for natural philosophers to employ causal terminology in formulating their explanatory claims. In this paper, I analyze this puzzle in light of Reid's distinction between efficient and physical causation —a distinction he grounds in his strict understanding of active powers. I consider several possible reasons that Reid may have for maintaining that natural philosophers ought to employ causal terminology and suggest that the underlying rationale for his views is his understanding of the aims of explanation and their connection to the interests of human agents. The ultimate aim of knowing the causes of phenomena is to mollify the natural intellectual curiosity of human inquirers and provide guidance that insures successful action. The discovery of laws governing phenomena fulfills this aim and, as such, it is appropriate for natural philosophers to employ causal terminology.
\end{abstract}

\section{Introduction}

Thomas Reid explicitly rejects the traditional view that the aim of natural philosophy is to discover the causes of phenomena. In its place, he proposes a Newtonian-inspired model in which the sole aim of natural philosophy is to discover the laws governing phenomena. He writes,

Former authors ancient and modern not excepting Francis Bacon, have conceived it to be the province of physics to discover the causes of the phenomena of nature...[but according] to Newton, when physics shall be carried to the utmost perfection, there would not be found in the whole science such a conception as that of a cause; nothing but laws of nature, which are general facts grounded on experience, and phenomena which 
are particular facts, included in the more general, and consequent upon them. ${ }^{1}$

But Reid also maintains that natural philosophy is a kind of causal inquiry. He asserts, "The whole business of physics is to discover, by observation and experiment, the laws of nature, and to apply them to the solution of the phenomena: this we call discovering the causes of things."2

The consistency of these claims depends upon Reid's contention that the term 'cause' has an equivocal meaning. Reid writes, "The word cause, is very ambiguous in all languages... The words power, agent, effect, have a like ambiguity; each different meaning of the first mentioned word leading to a corresponding meaning of the three last." In order to clarify his use of these terms, Reid introduces a distinction between efficient and physical causality. ${ }^{4}$ The efficient cause of a natural phenomenon is the agent, endowed with both will and intellect, that produces the phenomenon by the exercise of its active powers. ${ }^{5}$ Within the domain of natural philosophy, the term 'physical cause' refers primarily to laws governing natural phenomena. ${ }^{6}$ Thus, Reid maintains that natural philosophy is a form of causal inquiry only in the attenuated sense that it aims to discover the physical causes of phenomena.

Although the distinction between efficient and physical causality shows that it is possible to describe natural philosophy as a form of causal inquiry, it does not give one positive reasons to think that causal terminology ought to be employed in natural philosophy. This is puzzling given Reid's explicit recognition that the use of causal terminology causes significant misunderstanding concerning the achievements of natural philosophy. Reid writes, 
the ambiguity of the words cause, agency, active power, and the other words related to these, has led many to understand them, when used in natural philosophy, in a wrong sense, and in a sense which is neither necessary for establishing the true principles of natural philosophy, nor ever meant by the most enlightened in that science. To be convinced of this, we may observe that those very philosophers who attribute to matter the power of gravitation, and other active powers, teach us, at the same time, that matter is a substance altogether inert, and merely passive; that gravitation, and the other attractive and repulsive powers which they ascribe to it, are not inherent in its nature, but impressed upon it by some external cause, which they do not pretend to know or to explain. ${ }^{7}$

It is instructive, then, to consider whether Reid has positive reasons for maintaining that natural philosophers ought to employ causal terminology.

Reid scholarship has not addressed this particular question adequately because commentators often approach the distinction between efficient and physical causation with an eye towards other pressing concerns in Reid's work. Some scholars interested in Reid's conception of agency and its connection to debates about human freedom note the distinction between efficient and physical causation as a response to the apparently paradoxical implications of Reid's views on agency. For instance, Timothy O'Connor writes,

[Reid] claims that the notion of an agent directly bringing about some event (a volition) is the original and primary sense of the term 'cause'...[and this] implies a thesis repugnant to common sense (and in that respect very uncharacteristic of Reid ), viz., that the patterns of regularity that we observe between events (apparently) not under the direct control of any intelligent agent are not, properly speaking, indicative of genuinely causal relations. In order to avoid being understood as advancing a wildly implausible claim, he acknowledges at once "another meaning of the word cause, which is so well authorized by custom, that we cannot always avoid using it, and I think we may call it the physical sense". 8

Accordingly, Reid could contend that one ought to employ causal terminology in natural philosophy because of the entrenched function of causal language in common discourse. 
Any attempt to purge the vocabulary of causality from natural philosophy would violate the long-standing authority of customary usage and, hence, ought to be avoided.

Other scholars interested primarily in Reid's understanding of the methods and aims of natural philosophy note the distinction between efficient and physical causes in order to highlight Reid's novel interpretation of Newtonian natural philosophy. ${ }^{9}$ Steffen Ducheyne argues that "Reid took it that Newtonian science restricted itself—and philosophical inquiry should do so as well—to provide a nomological-necessitarian explanation of phenomena." ${ }^{\text {10 }}$ By employing the term 'physical cause', Reid could illuminate his strict demarcation between natural philosophy and metaphysical speculation concerning the ultimate efficient causes of phenomena. ${ }^{11}$ And given the common association between causation and explanation, use of the term 'physical cause' could reinforce the common understanding of natural philosophy as an explanatory project while signaling Reid's novel understanding of the nature of ultimate explanation in natural philosophy.

The central goals of this paper are (i) to explore these responses and (ii) to develop an account of Reid's positive case for the continued use of causal terminology in natural philosophy. I suggest that Reid draws a connection between the speculative and practical interests of human inquirers and the aim of explanation; it is this connection that provides the rationale for his claim that natural philosophers ought to employ causal terminology. Much of this discussion will require a precise characterization of the distinction between efficient and physical causation —a distinction best understood in light of Reid's account of active powers. So, the structure of this paper is as follows. In Section Two, I summarize Reid's account of efficient causality and physical causality. In 
Section Three, I develop an interpretation of Reid's positive philosophical case for the continued use of causal terminology in natural philosophy.

\section{Active Powers and Reid's Distinction between Efficient and Physical Causation}

Reid argues that powers are qualities or attributes of an agent that enable it to initiate activity and, thereby, to produce change. His understanding of efficient causation is grounded in this primitive notion of a power. He writes,

The exertion of active power we call action; and, as every action produces some change, so every change must be caused by some exertion, or by the cessation of some exertion of power. That which produces a change by the exertion of its power we call the cause of that change; and the change produced, the effect of that cause. ${ }^{12}$

It is important to note that Reid distinguishes between a power, the exercise or operation of a power, and the effect resulting from the exercise of a power. Only those endowed with a power can exercise it to bring about an effect.

But the exertion of a power depends upon the will of the agent to which the power belongs. Reid contends that the

only clear notion or idea we have of active power, is taken from the power which we find in ourselves to give certain motions to our bodies, or a certain direction to our thoughts; and this power in ourselves can be brought into action only by willing or volition. From this, I think, it follows, that, if we had not will, and that degree of understanding which will necessarily implies, we could exert no active power, and, consequently, could have none; for power that cannot be exerted is no power. It follows, also, that the active power, of which only we can have any distinct conception, can be only in beings that have understanding and will. Power to produce any effect, implies power not to produce it. ${ }^{13}$

Hence, Reid maintains that insofar as an agent with a power to produce an effect chooses not to exert its power, then the effect will not occur. While effects are essentially connected to their causes, the will of an agent is under no direct necessitation to exert itself; there is genuine indeterminacy in the production of an effect. 
The idea of power originates in an agent's reflection on the production of an event through the exertion of its will. It emerges very early in the cognitive life of a child as it learns that it can produce desirable states of affairs by an exercise of its will. From this, the child learns that these events depend upon the exertions of its powers and, thereby, acquires the idea of a power to produce an event. Reid writes,

I am rather inclined to think that our first exertions are instinctive, without any distinct conception of the event that is to follow, consequently without will to produce that event. And that finding by experience that such exertions are followed by such events, we learn to make the exertion voluntarily and deliberately, as often as we desire to produce the event. And when we know or believe that the event depends upon our exertion, we have the conception of power in ourselves to produce that event. This account of the origin of our conception of power, makes it to be the fruit of experience and not innate; though it must be as early as any deliberate voluntary exertion to produce a certain event. ${ }^{14}$

While it may be unproblematic to attribute causal powers to oneself given the awareness of one's own exertions, Reid recognizes that it is important to consider whether one can attribute efficient causality to physical entities. Furthermore, he understands the difficulties associated with determining whether physical entities can possess active powers. He writes,

The ambiguity of the words power, cause, agent, and of all the words related to these, tends to perplex this question. The weakness of human understanding, which gives us only an indirect and relative conception of power, contributes to darken our reasoning, and should make us cautious and modest in our determinations. ${ }^{15}$

In spite of these difficulties, Reid argues that there is no clear observational evidence grounding the attribution of active powers to physical entities. He asserts, "We perceive changes innumerable in things without us. We know that these changes must be produced by the active power of some agent; but we neither perceive the agent nor the power, but the change only." 16 
And if one attends to human agency, it is evident that volition is essential to the actualization of a human agent's active powers. It follows from this, according to Reid, that "if we had not will, and that degree of understanding which will necessarily implies, we could exert no active power, and consequently could have none: For power that cannot be exerted is no power." ${ }^{\prime 17}$ Hence, the clearest notion of active powers indicates that active powers can be predicated only of those entities with both intellect and will. One cannot attribute natural phenomena to the productive powers of physical entities as such since there is no evidence that they possess either intellect or will. Reid asserts, We judge of things unknown by what we know, and as we first know by consciousness that we think and act and feel pain and pleasure, we are by analogy rather than by reasoning led to think the same of other men; and indeed not only of other men but of other things. It is a discovery made by degrees, and by observation and instruction, that many of the things about us, are so very unlike to us as to be perfectly inanimate and unthinking. ${ }^{18}$

Nonetheless, Reid concedes that it is common practice to use terms implying that physical entities possess active powers. Reid traces this practice to the development of language at early stages in human history. The distinction between active and passive verbs emerged from the recognition of an essential difference between acting and being acted upon. But humans quickly began to apply active terms to entities which subsequent inquiry has shown to be purely passive. Ultimately, these primitive people misapplied active terms to passive entities because of the basic human desire to know the causes of various changes in the external world. Reid writes,

As there is no principle that appears to be more universally acknowledged by mankind, from the first dawn of reason, than that every change we observe in nature must have a cause; so this is no sooner perceived, than there arises in the human mind a strong desire to know the causes of those changes that fall without our observation. Felix qui potuit rerum cognoscere causas, is the voice of nature in all men. Nor is there anything that more early distinguishes the rational from the brute creation, than this 
avidity to know the causes of things, of which I see no sign in bruteanimals."19

When primitive people observed changes in physical bodies without detecting the agency responsible for these changes, they attributed the activity to the physical bodies themselves. Reid concludes,

it is a general prejudice of our early years, and of rude nations, when we perceive anything to be changed, and do not perceive any other thing which we can believe to be the cause of that change, to impute it to the thing itself, and conceive it to be active and animated, so far as to have the power of producing that change in itself. ${ }^{20}$

This prejudice is most likely rooted in the human tendency to make judgments concerning other entities by reference to human activities and qualities.

The human desire to know the causes of things did not affect primitive people alone. It also led philosophers to propose speculative conjectures concerning the underlying mechanisms and processes responsible for producing observable phenomena. Reid, in a sustained critique of these views, suggests that the limits of human understanding make it necessary to confess ignorance rather than to propose or endorse hypothetical speculation of this kind. ${ }^{21}$ Natural philosophers who frame these hypotheses are, in reality, revealing their ignorance rather than providing an illuminating understanding of physical phenomena. Reid asserts,

Nature is the name we give to the efficient cause of innumerable effects which fall daily under our observation. But if it be asked what nature? Whether the first universal cause, or a subordinate one, whether one or many, whether intelligent or unintelligent? Upon these points we find various conjectures and theories, but no solid ground upon which we can rest. And I apprehend the wisest men are they who are sensible that they know nothing of the matter. ${ }^{22}$

At most, experience indicates that there is some intelligent first cause but whether this cause acts immediately to bring about all natural phenomena or acts indirectly by 
endowing physical entities with powers to bring about these effects is beyond the limits of human understanding. ${ }^{23}$ So, all hypothetical conjectures are in reality veiled claims of ignorance concerning the underlying productive causes of phenomena; as such, they are unwarranted in natural philosophy.

Reid's analysis of the strict notion of efficient causation entails that no physical entity possesses genuine causal powers. But Reid allows a loose sense of the term 'cause' that has its proper place in natural philosophy. In fact, he asserts that the goal of natural philosophy is the discovery of physical causes. His most explicit description of the distinction between efficient causality and physical causality occurs in his correspondence with Lord Kames and Dr. James Gregory. Consider some representative passages:

[A] It is proper here to explain what is meant by the cause of a phenomenon, when that word is used in natural philosophy. The word cause is so ambiguous, that I fear many mistake its meaning, and take it to mean the efficient cause, which I think it never does in this science. By the cause of a phenomenon, nothing is meant but the law of nature, of which that phenomenon is an instance, or a necessary consequence...In natural philosophy, therefore, we seek only the general laws, according to which nature works, and these we call the causes of what is done according to them. But such laws cannot be the efficient cause of anything. They are only the rule according to which the efficient cause operates. A natural philosopher may search after the cause of a law of nature; but this means no more than searching for a more general law, which includes that particular law, and perhaps many others under it. ${ }^{24}$

[B] I likewise admit, laws of nature may be called (as they commonly are called) physical causes - in a sense indeed somewhat different from [efficient causes] - because laws of nature effect nothing, but as far as they are put to execution, either by some agent, or by some physical cause; they being, however, our ne plus ultra in natural philosophy, which professes to shew us the causes of natural things, and being, both in ancient and modern times, called causes, they have by prescription acquired a right to that name. I think also, and I believe you agree with me, that every physical cause must be the work of some agent or efficient cause. Thus, that a body put in motion continues to move till it be 
stopped, is an effect which, for what I know, may be owing to an inherent property in matter; if this be so, this property of matter is the physical cause of the continuance of the motion; but the ultimate efficient cause is the Being who gave this property to matter. ${ }^{25}$

[C] ...in theology and in metaphysicks, the most common sense [of the term cause] is that of agent or efficient cause...In physicks, and in all its branches, medicine, chymistry, agriculture, the mechanical arts, \&c...the most common meaning of cause is Hume's notion of it - to wit, something which goes before the effect, and is conjoyned with it in the course of nature. As this notion is vague and popular, philosophers, when they would speak more precisely of a cause in physicks, mean by it some law of nature, of which the phenomenon called the effect is a necessary consequence. $^{26}$

In these passages, there are several distinct uses of the term 'physical cause'. In

[A], Reid suggests that laws of nature governing particular phenomena or more general laws under which one can subsume particular laws are the proper meaning of 'physical cause' in natural philosophy. In [B], Reid again claims that laws of nature are physical causes of phenomena, but he also suggests that one could describe an inherent property of matter as a physical cause. Reid claims, however, that the ultimate efficient cause of the effect attributed to this property as a physical cause is the ultimate intelligent agentGod. In [C], Reid asserts that the most common meaning of 'physical cause' is the Humean notion of an antecedent of an empirical regularity. Physical causes, unlike efficient causes, are not genuinely active; they are incapable of initiating activity that results in the production of an effect.

\section{Reid's Positive Account of the Use of Causal Terminology in Natural Philosophy}

Given Reid's strict understanding of efficient causality, there is no question concerning the use of the term 'cause' in natural philosophy. Causation in natural philosophy is physical causation. Since natural philosophers can distinguish clearly 
between physical and efficient causality, one can think of natural philosophy as a form of causal inquiry. But this does not necessarily give one positive reason to think natural philosophers should employ causal terminology. Reid thinks that natural philosophers ought to employ causal terms while precisely characterizing its meaning so as to avoid the potentially misleading implications of causal terms. In the introduction, I noted that some scholars attempt to resolve this puzzle by citing Reid's account of the entrenched structure of language. Altering the language of common discourse would require making changes that would be difficult to achieve and would violate common sense. Others suggest that Reid's defense depends upon the common association between explanation and causation. By employing the terminology of physical causation, natural philosophers can secure the common view that natural philosophy is explanatory form of inquiry while contrasting ultimate explanation in natural philosophy with the kinds of explanation proper to metaphysics. In what follows, I consider these views in greater detail and suggest that Reid draws a connection between the aims of explanation the speculative and practical interests of human inquirers. It is this connection that grounds Reid's positive case for the continued use of causal terminology in natural philosophy.

Consider, first, the argument that the continued use of causal terminology in natural philosophy is proper given its entrenched status in the structure of language. Reid's etiological account of the misapplication of causal terms to physical entities holds that causal terminology has become an entrenched feature of language concerning physical entities. The human avidity to know the causes of phenomena coupled with the inability to detect the agents responsible for physical changes leads inevitably to the misapplication of causal terms to essentially passive physical entities. Although this 
established use is improper, a change to the structure of language is not feasible. It is much easier to continue using the term 'cause' and carefully correct any false implications resulting from employing this term when referring to physical entities. But there are two ways in which one can understand this authority of customary usage that ought to be considered independently. First, one might argue that the entrenched structure of human language makes the use of causal terminology unavoidable. Second, although it may possible to avoid employing causal terminology in natural philosophy, one could contend that the customary usage of causal terminology makes its use natural. Hence, one ought to employ causal terminology because failing to employ it is a violation of common sense.

While the misleading use of causal terms by common persons may be unavoidable, it is not entirely clear why this would apply mutatis mutandis to the use of causal terminology in natural philosophy. Reid admits that the common person's idea of a cause retains within it remnants of the original idea of a productive efficacy. He writes, "The vulgar, in their notion even of the physical cause of a phænomenon, include some conception of efficiency or productive influence. ${ }^{27}$ But the distinct understanding of physical causes as laws of nature in natural philosophy does not carry any connotation of causal efficacy. Reid writes

But Newton...has taught us to acquiesce in a law of nature, according to which the effect is produced, as the utmost that natural philosophy can reach, leaving what can be known of the agent or efficient cause to metaphysicks or natural theology. This I look upon as one of the great discoveries of Newton; for I know of none that went before him in it. It has new-modelled our notion of physical causes, but, at the same time, carried it farther from what I take to the original notion of cause or agent. ${ }^{28}$ 
Given that the notion of a physical cause in natural philosophy is even further removed from the original notion of a cause, it is unclear why one would think that causal terminology is unavoidable in natural philosophy. In fact, Reid's discussion of physical causes as laws suggests a mode for reducing causal vocabulary to statements about laws governing phenomena. In the context of natural philosophy, then, causal terminology is avoidable.

But this argument does not undercut the view that customary usage of causal terminology has made its use natural in the context of natural philosophy. Reid could argue the excision of causal language from natural philosophy does violence to the naturalness of employing this terminology. The long use of causal vocabulary, especially in relation to physical bodies, has made it natural, and hence an aspect of the common sense understanding of the physical realm, to think physical entities as causes. Although natural philosophers maintain that physical entities are essentially passive, it would be imprudent to frame their explanatory claims in a manner that violated the natural authority of the common belief that physical entities act as the causes of phenomena.

The naturalness of the use of causal terminology extends to the common association between causation and explanation. Hagit Benbaji characterizes this point as follows: "Reid knows that most of us are not scientists. But for him science answers exactly the same question that we address in our everyday explanations: what happened?"29 Typically, the common person is satisfied to answer this question by claiming that physical bodies possess powers to produce the phenomenon in question. Although the common person may be satisfied with this explanation, there is a complete 
story about the occurrence of phenomena that scientists seek to tell. The goal, however, is the same: to explain phenomena.

But natural philosophers explain phenomena by framing precise laws of phenomena grounded on substantive inductive evidence in the attempt to subsume phenomena under the scope of the law. Knowledge of these laws enables one to make highly successful predictions concerning the regularities in nature and the future occurrences of phenomena. This kind of inquiry aims to answer question of the form: "why did $x$ occur?" Understanding the laws of nature allows one to answer this kind of question thus: $x$ occurred because $x$ is a necessary consequence of an inductivelyestablished law. This knowledge allows one to make predictions concerning when $x$ would occur in the future and it allows one to "solve" phenomena in terms of their governing laws. Thus, employing the language of physical causality is valuable because it signals a novel understanding of the nature of ultimate explanation of phenomena in natural philosophy. Given the traditional understanding of the explanatory aim of natural philosophy, using causal terminology while explicitly acknowledging that it refers to laws alone allows one to maintain the connection between the achievements of natural philosophy and the notion of explanation.

I would like to suggest, however, that Reid's positive case for the continued use of causal terminology in natural philosophy is rooted in something much more fundamental than the effects of customary usage on (i) the naturalness of its continued employment and (ii) the association between causation and explanation. Although it is natural to employ causal terminology when referencing physical entities and there is a strong association in people's minds between explaining phenomena and knowing their 
causes, there is a deeper rationale underlying Reid's claims that one ought to employ causal terminology. Reid argues that the goal of explanation in natural philosophy and common life is the satisfaction of the intellectual and practical aims of human inquirers. Human concern with the causes of phenomena derives from two sources: intellectual curiosity and practical need. Hence, he observes,

With regard to the phænomena of nature, the important end of knowing their causes, besides gratifying our curiousity, is, that we may know when to expect them, or how to bring them about. This is very often of real importance in life; and this purpose is served by knowing what, by the course of nature, goes before them and is connected with them; and this, therefore, we call the cause of such a phænomenon. ${ }^{30}$

In Reid's estimation, the value of knowing the causes of phenomena stems from how human agents can employ this information in the prediction and control of events. The explanatory claims substantiated by the methods of natural philosophy provide a kind of knowledge that is beneficial to the agent both in terms of the satisfaction of its natural curiosity and in terms of its actions. ${ }^{31}$

The common person, then, employs the term 'cause' to refer to the antecedent of an established empirical regularity and uses this understanding to plan and execute his actions. The natural philosopher employs the term 'cause' to refer to a law of nature and uses this understanding to provide an account of various phenomena and to ground predictions concerning future occurrences of phenomena. The precise understanding of the relations between phenomena serves to mollify the natural intellectual curiosity of human nature. Knowledge of the precise laws governing phenomena is a reliable guide in directing one's actions. It grounds an understanding of phenomena that allows for careful planning and execution of one's actions. This knowledge insures that the agent can reliably achieve its goals by the exercise of its active powers. So, Reid's positive 
case for the use of causal terminology in natural philosophy is grounded in the aims and interests of human inquirers who can use the knowledge of physical causes to their benefit in their actions as agents. The rationale for knowing the causes of phenomena stems from the real speculative and practical interests of human inquirers. Since natural philosophy satisfies the intellectual curiosity and practical needs of human agents, it satisfies the ultimate aim of explanation. Hence, natural philosophy is properly considered a kind of causal inquiry and, as such, natural philosophers ought to employ causal terminology in the formulation of their explanatory claims.

${ }^{1}$ Thomas Reid, "Of Power," The Philosophical Quarterly 51 (2001), 7.

${ }^{2}$ Thomas Reid, "Correspondence of Dr. Reid" in The Works of Thomas Reid, Vol. I., ed. William Hamilton (Bristol: Thoemmes Press, 1994), 65. Hereafter, "Correspondence". ${ }^{3}$ Thomas Reid, "Correspondence," 65.

${ }^{4}$ But he quite clearly rejects the view that these are two species of a common genus. In reality, these are specifications of distinct uses for a common term. For more on this issue see Hajit Benbaji, "Reid on Causation and Action," The Journal of Scottish Philosophy 1 (2003): 1-19.

${ }^{5}$ For more discussion of Reid's account of causation in relation to his account of agency see Edward Madden "Commonsense and Agency Theory," Review of Metaphysics 36 (1983): 319-341; William Rowe, Thomas Reid on Freedom and Morality (Ithaca: Cornell University Press, 1991); Timothy O'Connor, "Thomas Reid on Free Agency," Journal of the History of Philosophy 32 (1994): 605-622; Dale Tuggy, "Thomas Reid on Causation,” Reid Studies 3 (2000): 3-27; and Gideon Yaffe, Manifest Activity: Thomas Reid's Theory of Action (Oxford: Clarendon Press, 2004).

${ }^{6}$ Sometimes Reid employs the locution 'natural cause' instead of 'physical cause'. I take these notions to be synonymous and, thus, use only the term 'physical cause' in this paper. ${ }^{7}$ Thomas Reid, "Essays on the Active Powers of Man," in The Works of Thomas Reid, Vol. I., ed. William Hamilton (Bristol: Thoemmes Press, 1994), 525. Hereafter, EAP.

${ }^{8}$ Timothy O'Connor, "Thomas Reid on Free Agency," 607. For a similar kind of response see William Rowe, Thomas Reid on Freedom and Morality, 49-55.

${ }^{9}$ For more on Reid's Newtonianism see Larry Laudan, "Thomas Reid and the Newtonian Turn of British Methodological Thought," in The Methodological Heritage of Newton, ed. Robert Butts and John W. Davis (Toronto: Toronto University Press, 1970), 103-31; Richard Olson, Scottish Philosophy and British Physics 1750-1880: A Study in the Foundations of the Victorian Scientific Style (Princeton: Princeton University Press, 1975); Robert Callegaard, "The Hypothesis Of Ether And Reid's Interpretation Of Newton's First Rule Of Philosophizing." Synthese 120 (1999): 19-26; "Reid and the Newtonian Forces of 
Attraction.” The Journal of Scottish Philosophy 3 (2005): 139-155, and An Essay on Thomas Reid's Philosophy of Science. (Stockholm: Stockholm Universitet, 2006); Shannon Dea, "Thomas Reid's Rigourised Anti-Hypotheticalism," The Journal of Scottish Philosophy 3 (2005): 123-138; Steffen Ducheyne, "Reid's Adaptation and Radicalization of Newton's Natural Philosophy," History of European Ideas 32 (2006): 173-189; Rebecca Copenhaver, "Is Reid a Mysterian?," Journal of the History of Philosophy 44 (2006): 449-466; and Ryan Nichols, "Natural Philosophy and its Limits in the Scottish Enlightenment," The Monist 90 (2007): 233-250.

${ }^{10}$ Steffen Ducheyne, "Reid's Adaptation and Radicalization of Newton's Natural Philosophy," 180.

${ }^{11}$ Ryan Nichols, "Natural Philosophy and its Limits in the Scottish Enlightenment," Monist 90: 233-250 expresses deep concerns about the grounds of Reid's distinction between natural philosophy and metaphysics.

${ }^{12}$ Thomas Reid, EAP, 515.

${ }^{13}$ Thomas Reid, EAP, 523

${ }^{14}$ Thomas Reid, "Of Power," 3.

${ }^{15}$ Thomas Reid, EAP, 522.

${ }^{16}$ Thomas Reid, EAP, 522.

17 Thomas Reid, EAP, 523.

${ }^{18}$ Thomas Reid, "Of Power," 5. It is important to note Reid is rejecting the view that one can know the underlying efficient causes of phenomena (whatever they are). He is not asserting that there are no physical efficient causes; he is merely asserting that even if there were, natural philosophers lack the means to discover them.

${ }^{19}$ Thomas Reid, EAP, 516.

${ }^{20}$ Thomas Reid, EAP, 516.

${ }^{21}$ It is clear that Reid takes Newton to be the source of this idea, but it is not clear that Reid interpreted Newton's injunction against framing hypotheses accurately. See the works cited in footnote 9 for futher discussion of this issue.

${ }^{22}$ Thomas Reid, EAP, 522. This passage seems to imply that unintelligent entities could act as efficient causes if God chose to use them in this manner. This seems puzzling at best if Reid maintains that physical entities in virtue of lacking a will and intelligence cannot be causes in the strict sense required by his analysis of efficient causation.

${ }^{23}$ It seems that Reid is countenancing the possibility that the first cause could endow physical entities with genuine causal powers. It is not clear that this is consistent with his view that physical bodies are essentially passive, but I cannot address this puzzle in this paper.

${ }^{24}$ Thomas Reid, "Correspondence," 57-58.

${ }^{25}$ Thomas Reid, "Correspondence," 73.

${ }^{26}$ Thomas Reid, "Correspondence," 84.

${ }^{27}$ Thomas Reid, "Correspondence," 76.

${ }^{28}$ Thomas Reid, "Correspondence," 76.

${ }^{29}$ Hagit Benbaji, "Reid on Causation and Action," Journal of Scottish Philosophy 1 (2003): 7.

30 Thomas Reid, EAP, 526. 
${ }^{31}$ According to Reid, knowledge of the real efficient causes of phenomena does not concern the majority of human inquirers because it is not useful in one's ordinary activities. See Thomas Reid, EAP, 522. 